\title{
The New Scientism in Legal Scholarship: A Comment on Clark and Posner
}

George L. Priest ${ }^{\dagger}$

Professor Clark's paper is surely the most self-consciously scientific of those delivered at the symposium. In aspiration it resembles the work of Professor Posner, ${ }^{1}$ who is famous for his contributions to the scientific study of the legal system. The approach of these scholars exemplifies a growing adoption of the scientific style in legal scholarship. Although social scientists have occasionally addressed subjects relating to the law, their interest in the legal system typically has been tangential. In contrast, this modern legal scholarship boldly attempts a comprehensive examination of the institutions of the law with the methods of the sciences. Most prominent is the work of what is now a substantial group of scholars, led by Professor Posner, who contend that the universe of common law rules exhibits a single scientific regularity: the rules are, in the terms of economics, efficient. Professor Clark's charge to us is equally ambitious. He would have us examine the development over time of all legal doctrines in terms of the biological process of evolution.

The attraction of the scientific method, of course, is the seeming precision and power that it brings to analysis of the legal system. Scientific propositions, as Professor Clark frequently informs us, are "testable." 2 They can be confirmed or refuted, unlike the invocation of (often personal) values that is characteristic of ordinary legal scholarship. Science offers the legal world the possibility of consensus once "general laws of [legal] change"3 are discovered.

In this Comment I argue that the contribution of this modern work to our understanding of the legal system is greatly exaggerated. A very large proportion of this work is scientistic and, in essence,

$\dagger$ Professor of Law, Yale University.

I wish to thank Kenneth I. Wolpin and Stuart Bauchner for helpful comments and other assistance. I am responsible for errors.

1. Professor Posner alludes to this work in his symposium piece. See Posner, The Present Situation in Legal Scholarship, 90 YALE L.J. 1113, 1119-21 (1981).

2. E.g., Clark, The Interdisciplinary Study of Legal Evolution, 90 YALE L.J. 1238, 1258 . 59 (1981).

3. Id. at 1260 . 
alien to the sciences from which it seems to derive. More generally, I believe, the aim to construct a comprehensive theory of legal doctrines-whether economic or biological-represents, in our present state of knowledge, a perversion of the scientific enterprise. In this respect, the scientific methods of Professors Clark and Posner are similar and bear closer examination.

\section{Clark's Scientific Method}

Let us first review the method of Professor Clark, which derives from biology and compares change in legal institutions to the biological process of evolution. According to Clark's method, a scholar first must immerse himself in a field of law and progressively distill the large and detailed mass of legal rules until a small and manageable number of central features remains. In this manner, Clark himself has identified the four principles of corporation law, the seven postulates of corporate income tax, the four stages of capitalist enterprise, the five phases of corporate reorganization, and the five stages of remedies for creditors of businesses. ${ }^{4}$ Each of these phases or stages is an archetypical form, representing a distinct point in the development of the field. Clark calls them "starting points," but they are at once end-points of one line of development and starting points of another, in the manner of a chain of development over time.

In the second step of Clark's method, the scholar inquires how the identified stages differ from each other. Once the relevant differences are made clear, the scholar specifies the principles of development from stage to stage; that is, both the "motor" of changes and the environmental conditions that have influenced the rate or direction of the trend. As a final step, the scholar attempts to tie together the explanations of the trends of development between the various stages. With luck, it is possible to devise a comprehensive explanation-an explanation of the trend between stage one and stage two that is consistent with the explanations of the trends between stages two and three, three and four, and so on. It is at this point, according to Clark, "where the hard work comes in, and where the methodology of the social sciences may be of use." ${ }^{8}$ Clark advises us to examine the various social sciences to find which of them-economics, sociology, psychology, for example-most clearly illuminates the particular data under study. ${ }^{\text {? }}$

4. For synopses of Clark's studies, see id. at 1243-56.

5. Id. at 1257.

6. Id. at 1258 .

7. Id. at $1260 \cdot 65$. 
Clark admits that it is not always possible to discover a single explanation for the various changes from stage to stage. Thus, Clark explains that four of the five phases of corporate reorganization-although not all five-develop from "a need for more numerous or exacting valuation procedures." 8 Furthermore, sometimes there are multiple rather than single determinants of specific trends in the law whose influence is likely to be difficult to disaggregate. For example, Clark finds the four principles of corporation law to have derived from "technological changes ... [that made] large-scale industries . . . feasible," plus an increase in the "general level of wealth," which remained "not extremely lopsided in distribution," plus, finally, the acceptance of "private ownership of capital goods . . . as a social and legal norm."

Nevertheless, Cilark's own work seems to show that reasonably simple and straightforward explanations can be discovered for developments in what appear to be very complex fields. Indeed, on the basis of these several studies, Clark is able to transcend specific discoveries to identify evolutionary principles of even greater generality. In five of the six areas of the law Clark gives as examples, the stages and trends illustrate a general law of "primary cost reduction," the reduction by institutional design of costs of imperfect information, risk, and uncertainty (that is, transaction costs). ${ }^{10}$ Furthermore, Clark finds that once a principal institutional stage has been strongly established, there occurs what he calls "secondary cost reduction": the "lengthy, complex efflorescence of doctrinal detail" to elaborate and refine the particular central institutional form. ${ }^{11}$ Secondary cost reduction ococcurs in response to the continual effort of affected parties "pushing to modify the legal landscape in a direction favorable to [their] interests."12

Clark has discovered, however, one exception to the general laws of primary and secondary cost reduction. The field of corporate taxation exhibits a different form of evolution. The seven starting points of corporate taxation derive not from cost reduction but, echoing Malthus and Darwin, from the "continued struggle among opposing groups over externally fixed resources." ${ }^{13}$ As a consequence, Clark
8. Id. at 1250 .
9. Id. at 1243 .
10. Id. at 1241-42.
11. Id. at 1242.
12. Id. at 1247 .
13. Id. at 1256 . 
observes evolution toward "cumulative complexity of legal rules without any offsetting social efficiencies."14

\section{Posner's Scientific Method}

Now let us examine Professor Posner's method for the study of his hypothesis that common law rules are efficient. ${ }^{15}$ Some critics have alleged that Professor Posner's efficiency hypothesis derives from his political views or interests. From the standpoint of scientific evaluation, however, Professor Posner's personal views are irrelevant. Indeed, whether or not Professor Posner can defend himself against this accusation, critics of his theory are obliged to consider the best scientific case that can be made for his hypothesis.

Strictly stated, Posner's hypothesis is that common law principles serve to optimize the sum of costs and benefits for parties subject to them. ${ }^{10}$ Why common law principles possess this characteristic is not known, but the proposition nonetheless provides a means for deducing specific and observable outcomes. The hypothesis is tested by surveying leading decisions of a variety of unrelated fields to determine whether the legal rules embodied in the decisions are efficient. A serious weakness of this method of evaluation is that information about costs and benefits is drawn solely from appellate opinions. Because the "economic logic" of the common law is implicit rather than explicit, ${ }^{17}$ appellate opinions seldom contain estimates of costs and benefits sufficiently precise for careful confirmation of the hypothesis, a problem that is particularly acute where legal principles of substantial generality are at issue. This weakness, however, is regarded chiefly as a problem of measurement rather than of theory. Furthermore, the problem of measuring the efficiency of specific rules becomes less significant where support for the hypothesis is cumulative. Thus, it is important to the credibility of the theory that evidence in its favor can be found in an extraordinary variety of what otherwise appear to be unrelated or loosely related legal fields. In addition, cu-

14. $I d$.

15. The theories of Professors Clark and Posner are similar in respects besides method. Posner's efficiency-of-the-law hypothesis is only a more rigorous form of Clark's "primary" and "secondary" laws of change. Clark, at various points, hedges his hypothesis by incorporating concerns about the distribution of wealth and "social or legal norms" as determinants of change. Because those determinants cannot be measured, however, the seemingly greater breadth of Clark's theory is not an advantage. For a related criticism of Professor Clark's theory, see p. 1290 infra.

16. See R. Posner, Economic Anazysis of Law, passim (2d ed. 1977).

17. See id. at 179, 181; Coase, The Problem of Social Cost, 3 J.L. \& Econ. 1, 22 (1960). 
mulative support for the hypothesis diminishes concern over the failure to identify a mechanism generating efficient rules. If one finds confirming evidence of the efficiency hypothesis in fields as diverse as rescue law, corporation law, and First Amendment law, one has discovered a scientific proposition-like the laws of gravity or the preMendelian process of natural selection-of substantial generality and importance, even if the precise mechanism of its operation is unclear.

\section{The Scientific Methods of Clark and Posner Compared}

How are the scientific methods of Clark and Posner similar, and what does the similarity tell us about the modern scientific study of the legal system? Both scholars attempt to apply to law the rigorous methods of establisized sciences: one calls on biology, and the other, economics. The more significant and curious similarity is that the methods of scientific inquiry applied by Clark and Posner have been abandoned by practicing scientists in the fields of biology and economics. Both Clark and Posner bring to the study of the legal system scientific methods discredited in the sciences from which their analyses derive.

Professor Clark, for example, borrows from biology a very primitive theory of evolutionary change. His method of analysis most closely resembles the form of typological study characteristic of biology in the late eighteenth century, when scientific endeavor focused on the identification of ideal types and of differences between these types. ${ }^{18}$ There is less stasis in the world of Professor Clark than in eighteenth-century natural science, but an idea common to both is that evolution proceeds in steps or jumps between distinct and unique stages. ${ }^{19}$ Clark's general law of secondary cost reduction borrows from a different biological tradition. Secondary cost reduction closely resembles Lamarckism: the theory that the constant and repeated use of characteristics of some type (Lamarck's organs or Clark's legal rules), accompanied by efforts of organisms or individuals to make the most of the characteristics in their respective environments, strengthens and enlarges the characteristics. ${ }^{20}$ Thus the expanding neck of Lamarck's giraffe and the detailed "efflorescence" of Clark's rules. ${ }^{21}$

18. See A. Lovejoy, The Great Chain of Being 251-52 (1936); E. Mayr, Typological versus Population Thinking, in Evolution AND THE DIversity OF LifE 26 (1976).

19. There appears also, in both conceptions, a sense of ever-increasing progress. See, e.g., C. Gillispie, Genesis ANd Geology 204 (1951); A Lovejoy, supra note 18, at 242-62.

20. See E. MAYr, Lamarck Revisited, in Evolution AND THE Diversity of Life 222 (1976).

21. The comparison of Clark to Lamarck is accurate, but somewhat unfair. Lamarck's 
My point is not to challenge Professor Clark's theory of evolution, but to note the curious nature of his application of biological method. Clark ignores methodological advances in biology that are responsible for many of its modern achievements and that would have informed and substantially enriched his study of legal phenomena.

The principal methodological advance of nineteenth-century natural science was the idea of uniformitarianism, which proposes that natural forces operating in the past are similar to forces operating in the present. ${ }^{22}$ The implication of the uniformitarian approach is to render illusory the theory of stages or phases that are in any meaningful way distinct. The only changes that occur are those that can be observed each day-small changes, perhaps imperceptible at the level of the single observation.

Uniformitarianism transformed the study of biology, not because it more accurately estimated the true specific rate of natural change, but because it is methodologically superior to both typological and catastrophic approaches. The uniformitarian proposition vastly increases the number and range of observations available to confirm or refute a specific hypothesis. ${ }^{23}$ The uniformitarian approach would greatly ease the labor of testing Clark's theories. Professor Clark, presumably, would test his corporation law hypothesis by a tedious and extremely problematic collection of data on the size and distribution of wealth over the last two hundred years. ${ }^{24}$ Compare the method of the uniformitarian, who would test the hypothesis by observing the relationship between corporation law and the distribution of wealth at some specific time-today or at any other period for which data are available.

The uniformitarian approach was instrumental in the late eighteenth and nineteenth centuries in the supercession of the Baconian inductive method of science by the modern hypothetico-deductive method. Professor Clark's scientific method for the study of the law is essentially inductive. According to Clark, the scholar collects data relevant to some legal field with few if any preconceived ideas, and studies

damaged reputation as an evolutionary theorist stems from his failure to explain the transmittal to subsequent generations of characteristics developed by use or disuse. The mechanism of transmittal of legal characteristics in Clark's theory is much more plausible.

22. See M. Ghiselin, The Triumph of the Darwinian Method 13-18 (1969); C. GillispIE, supra note 19, at 121-48; E. MAYR, The Nature of the Darwinian Revolution, in Evolution AND THE Diversity OF LIFE 277 (1976); Rudwick, Uniformity and Progression: Reflections on the Structure of Geological Theory in the Age of Lyell, in Perspectives in the History of Science and Technology 209 (D. Roller ed. 1971).

23. See M. Ghiselin, supra note 22 , at 14.

24. Clark, supra note 2, at 1242-47. 
the data with the objective of defining broader and broader generalizations about the field. ${ }^{25}$ This approach is very similar to Bacon's method-now, of course, discredited-of induction by exclusion: of progressing from observations of the lowest universals to axioms of the greatest generality. ${ }^{28}$

Although the Baconian method was responsible for substantial scientific advance, it was recognized in the nineteenth century that the method of investigation was basically ad hoc and inclined toward tautology. ${ }^{27}$ Professor Clark emphasizes the testing of hypotheses in order to avoid tautology. But the ad hoc character of his method is evident, in particular, in his acceptance of partial explanations of his data. As mentioned earlier, Clark is satisfied if, say, four of five legal stages can be explained according to one theory with the fifth stage explained according to a different theory, ${ }^{28}$ a failing common to the Baconian inductive approach. Applied rigorously, the uniformitarian proposition would not allow partial explanations of this nature.

Professor Posner's application of economics to the legal system, in contrast, is in no respect inductive. Posner formulates a hypothesis that he proceeds to test by the examination of fresh evidence. Professor Posner's specific hypothesis, however, is as peculiar and as foreign to positive economics as Clark's application of evolutionary ideas is to biology. Indeed, Posner's efficiency-of-the-law hypothesis has no relation to positive economics as we know it. The efficiency hypothesis alludes to economics; the determinants of rules are costs and benefits. But the science of economics, as Professor Posner has taught us, is the science of constrained choice, of equilibria subject to cost constraints. In Professor Posner's model, however, there is no individual

25. See D. Hull, Darwin and His Critics 9 (1973).

26. See F. BAcon, The New Organon $129-52$ (F. Anderson ed. 1960) (1st ed. 1620) (aphorisms 9-16 of Book II); D. HuLx, supra note 25, at 21.

Professor Clark's criticism of one of my papers, see Clark, supra note 2, at 1266.72, resembles the classic debate between inductive and deductive scientists. See D. HuLL, supra note 25 , at 9 . Clark criticizes my theory as empirically meaningless. Similarly, the most common objection by inductivists to Darwin's (deductive) theory was that it rested on hypotheses relating to unobservable and unknowable phenomena. Id. at 33. The principal grounds of disagreement, however, are scientific method and the nature of acceptable proof. In my view, my theory of the selection of efficient rules can be tested and would be supported by a demonstration that cases in which the stakes to the parties are higher are litigated more frequently. Such a demonstration would be similar to the support offered to the theory of natural selection by evidence of differential rates of reproductive success.

27. See M. Ghiseun, supra note 22, at $39-40$.

28. See p. 1286 supra. In this respect, Professor Clark's theory resembles saltatory theories of evolution. 
maximizing behavior, there is no mechanism for the equilibration of individual decisions (no market), there is no conception of the margin or of marginal changes in behavior in response to marginal changes in costs. Posner's model shares none of the defining characteristics of positive economics.

Professor Posner and others have attempted to discover how costs might constrain the judicial choice among legal rules. Thus, they have studied advancement patterns in the judiciary as a function of the frequency of citation or of affirmance-reversal rates. ${ }^{29}$ But these attempts seem half-hearted, and understandably so: their results have failed to confirm the hypothesis.

From the standpoint of positive economics, the peculiar aspect of Professor Posner's work is his discovery of efficiency in the complete absence of individual maximizing decisions. In the world of Professor Posner, the society somehow devises perfectly cost-optimizing legal rules. Studies in positive economics, in contrast, never discover or even attempt to discover "efficiency." Such studies are fortunate if the direction of a change in behavior can be specified and observed unambiguously. The efficiency concept is employed in other forms of economic work: efforts to devise models describing the characteristics of optimal institutions or regimes. The function of these economic studies, however, is chiefly normative. They inform the utilitarian policymaker of optimal decísions.

Professor Posner, however, has turned this style of economics on its head; that is why there has been so much confusion about the normative or positive basis of his work. ${ }^{30}$ Posner's method is that of normative economics steadfastly employed toward positive ends, a positive theory of social values ${ }^{31}$ rather than of social behavior. The character of Posner's work thus is alien to both positive and normative economics and has no analogue among the work of practicing economists. $^{32}$

In my view, however, Professor Posner's departure from the normal method of economics is more that a curious eccentricity. Posner's hypothesis and his work attempting to support it are in essence anti-

29. Higgins \& Rubin, Judicial Discretion, 9 J. Lecal Stud. 129 (1980); Landes \& Posner, Legal Change, Judicial Behavoir, and the Diversily Jurisdiction, 9 J. LEGAL STUD. 367 (1980).

30. See, e.g., Buchanan, Good Economics-Bad Law, 60 VA. L. REv. 483, 485 (1974).

31. As a theory of values, Posner's is a simple theory with a very simply defined judicial utility function.

32. Posner's method resembles that of the famous article by Gary Becker, Crime and Punishment: An Economic Approach, 76 J. PoL. EcoN. 169 (1968), although Becker admits that his objective is normative, $i d$. at $169-70$. 
thetical to the economic theory of behavior. If Posner were correct that all legal rules or principles are efficient, he would have discovered the single most powerful empirical contradiction of all time of the economic theory of behavior, of far more significance than the work of Kennedy, ${ }^{33}$ Kelman, ${ }^{34}$ or Twersky and Kahneman ${ }^{35}$ in their oblique challenge to the behavioral assumptions of economics. Posner's finding, if correct, would subvert positive economics because it would demonstrate that in a significant area of human behavior, an economic equilibrium can result without any of the prerequisites of equilibrium: without individual maximizing decisions, without even the existence of a market or of a shadow market. Such a finding would challenge every empirical result consistent with the theory of individual behavior in markets because it would provide evidence that individual behavior is irrelevant to equilibrium. The market itself may be an epiphenomenon.

\section{The Modern Scientific Study of the Law}

My purpose in these comments is not to criticize the substance of Glark's or Posner's theories, but to illustrate a central problem that accompanies the introduction of the scientific method into legal discourse. We must ask how we can explain the peculiar application of scientific methods by these two scholars. It is an important question because of the very high abilities of both of them. Clark and Posner are probably the two most prolific scholars of the day; they are also the two with the widest range of expertise and interest. Why is their science so inadequate, and what does their example portend for what I have called the rise of "scientism" in legal scholarship?

The answer, I believe, is that both Clark and Posner are lawyers whose principal interest is legal phenomena. The method of both scholars is to employ scientific theory, but only as a tool to illuminate the legal system that is their particular focus of interest. This method is much different from that of an economist or biologist. The economic theorist is interested principally in defining the characteristics

33. Kennedy, Cost-Benefit Analysis of Entitlement Problems: A Critique, 33 SraN. L. REV. 387 (1981).

34. Kelman, Consumption Theory, Production Theory, and Ideology in the Coase Theorem, 52 S. CAL. L. Rev. 669 (1979); Kelman, Spitzer and Hoffman on Coase: A Brief Rejoinder, 53 S. CAL. L. REv. 1215 (1980); M. Kelman, Unpublished discussion notes for Yale Law School Legal Theory Workshop (Oct. 11, 1979).

35. Twersky \& Kahneman, The Framing of Decisions and the Psychology of Choice, 211 ScI. 453 (1981). 
of economic behavior. Some hypothesis with respect to economic behavior may lead the economist to the law if the legal example is particularly revealing or the legal data particularly rich. But the economist has no interest in explaining law in any comprehensive way or in explaining the law at all, except perhaps as a by-product of the economic investigation. That is why in most studies of legal phenomena by economists, the explanation of law, as opposed to the explanation of behavior, appears to lawyers hopelessly incomplete and naive.

Science as typically practiced in law schools is much different. It is the law that is to be explained, with whatever scientific techniques are available. In his oral remarks at the symposium, Professor Clark urged us to be "opportunistic," "to raid the social sciences for whatever theories are of value."36 Similarly, Professor Posner has answered the criticism that his theory ignores individual maximizing behavior by recounting the diverse areas of law that the theory explains. These methods, however, represent a form of corruption of the scientific process that is insufficiently emphasized in considerations of law and the social (or natural) sciences. In bringing a scientific theory to a specific phenomenon, one loses sight of the tentative and exploratory nature of scientific propositions. Seldom does such a study show more than that the legal data are not inconsistent with some scientific theory. The study of law and the social sciences seldom contributes to the advance of theory itself.

Although one frequently hears that the social sciences offer a more rigorous way to study law than do the more traditional forms of scholarship, I believe the reverse is true. The theoretical commitment of most "scientific" studies of the law is weaker and more suspect, especially in studies conducted by lawyers. Lawyers are individuals who by their investment of many years in obtaining a legal education have demonstrated their belief that the law and legal institutions are uniquely important in themselves, a belief hostile to any purely scientific theory. Scientific studies of legal phenomena must be regarded with greater skepticism than studies in the underlying sciences themselves because the method of legal studies is most often unscientific. Lawyers who practice social science in law schools exploit the successes of true scientists in the underlying disciplines and ride free on their reputation for scientific integrity. Part of Professor Posner's work suggests an example. His production of books and articles addressing the efficiency hypothesis-however convincing-is impressive

36. See Clark, supra note 2, at $1263-65$ (urging opportunism in use of social sciences). 
to us all. But imagine the submission of the same material by a junior faculty member for promotion in any decent economics department. On the other hand, Professor Posner has completed many scientific papers of the highest merit. ${ }^{37}$ But these are unknown to the legal profession.

The weakness of scientific studies of the legal system derives, I believe, from both the demand for relevance and the tolerance of relevance. In most law schools, an economist, sociologist, or political scientist must demonstrate some talent or interest relevant to professional training in the law. The law school not only diverts the purely scientific interests of these theorists but corrupts them by providing incentives to redirect the scientific method toward what may be of use in legal practice. The demand for relevance affects lawyers as well. Lawyers whose interest in social science derives from an interest in contract or antitrust law, as opposed to contract or antitrust behavior, cannot be theorists and cannot be counted to contribute in even a supportive role to theory, except as they might contribute to legal theory. ${ }^{88}$

More destructive of science in legal scholarship is the tolerance of relevance. It is not uncommon for social scientists (including lawyers only interested in social science) to be promoted to positions in law schools on the basis of work purely derivative of some underlying scientific discipline or on the basis of no mare than collaboration with a lawyer. It is for this reason that, with very few exceptions, most social scientists in law schools are essentially gifted teachers of undergraduates, and not theorists of the first rank. Before applications of the scientific method by the faculties of law schools can contribute to scholarship, social scientists and lawyers interested in the social sciences must be evaluated by their contribution to the scientific disciplines themselves, rather than by the acceptance of their work by unexpert student editors of law journals.

Personally, I believe that social science is possible and that it might contribute to the understanding of human behavior and of related legal phenomena. But law schools must resist the temptation to pollute the scientific enterprise with concerns of relevance. One of Darwin's most convincing papers in support of his theory of biogeography

37. E.g., Posner, The Behavior of Administrative Agencies, 1 J. LEgal Stud. 305 (1972).

38. Perhaps this is what my colleague Bruce Ackerman means by the "new doctrinalism." See Ackerman, The Marketplace of Ideas, 90 YALE L.J. 1131, 1131-32 (1981) (describing recent application of social science analysis to legal problems as newer version of doctrinal analysis). 


\section{Comment on Clark}

addressed the influence of saltwater on seed growth. ${ }^{39}$ If Darwin had been a faculty member of a eugenics institute, charged with training students in the methods of artificial selection for animal breeding, the paper would have appeared the project of a madman. Lawyers interested in the social sciences and social scientists in law schools are in a similar position today.

39. Darwin's findings provided evidence suggestive of the types of plants that could be expected to survive sea transport to islands, and thus enabled the tracing of the evoIutionary descent of novel island species. C. DARwIN, On the Action of Sea-Water on the Germination of Seeds, in 1 The Collected Papers of Chardes DARwin 264 (P. Barrett cd. 1977). The paper is discussed in M. Griselin, supra note 22, at 40. 